\section{Duodenal Metastases from Lung Cancer}

Primary duodenal cancer is more common than metastatic disease to the duodenum (1). Direct extension of pancreatic cancer is the most common offender of duodenal integrity (2). Lung carcinoma metastasizing to the small intestine is uncommon. We have recently encountered a case of a 62-year-old woman with squamous-cell of the lung cancer who underwent upper endoscopy for gastrointestinal bleeding. In the third portion of the duodenum, a $3-\mathrm{cm}$ exophytic friable mass with a central small ulcer with a red spot was noted (Figure 1). No active bleeding was observed. No endoscopic therapy was performed. Biopsies obtained from the periphery of the lesion revealed squamous-cell carcinoma (Figure 2 ). She rapidly deteriorated, and died two weeks later of progressive cancer, without any further evidence of gastrointestinal bleeding. No autopsy was performed.

Among the different histologic types of lung cancer, squamous-cell lung cancer tends to be least commonly associated with extrathoracic metastases (3). Richie et al. (1) found a patient with a squamous-cell carcinoma of the lung causing small-bowel obstruction due to a jejunal intussusception. McNeill et al. (3) found 15 patients with lung cancer to have small-bowel metastases, but none of these were in the duodenum. The most common gastrointestinal manifestations of lung cancer metastatic to the small intestine, regardless of histologic type, are perforation and obstruction (3). Upper gastrointestinal bleeding from a large-cell undifferentiated carcinoma of the lung producing a superior mesenteric artery to duodenum fistula (4), and occult bleeding from a large-cell bronchogenic carcinoma metastatic to the jejunum (5), have been reported. However, bleeding due to direct deposits of squamouscell lung cancer in the duodenum, as in our case, has not been reported. Metastatic squamous-cell lung cancer to the upper gastrointestinal tract should be considered in the differential diagnosis of patients harboring such a malignancy who have gastrointestinal bleeding.

\section{Raijman}

Section of Gastrointestinal Oncology and Digestive Diseases, M.D. Anderson Cancer Center, University of Texas, Houston, Texas, U.S.A.

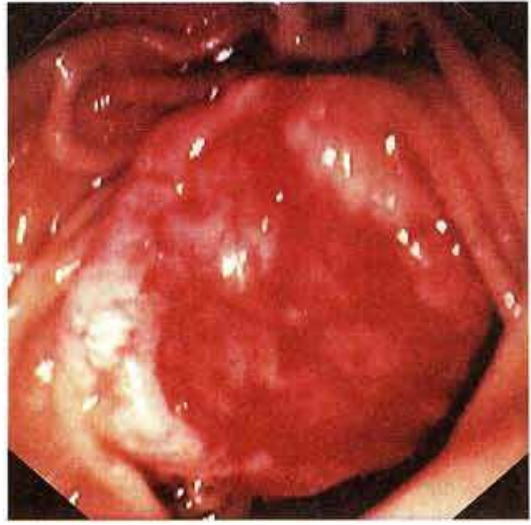

Figure 1:

Endoscopic picture showing an exophytic friable mass in the third portion of the duo denum.

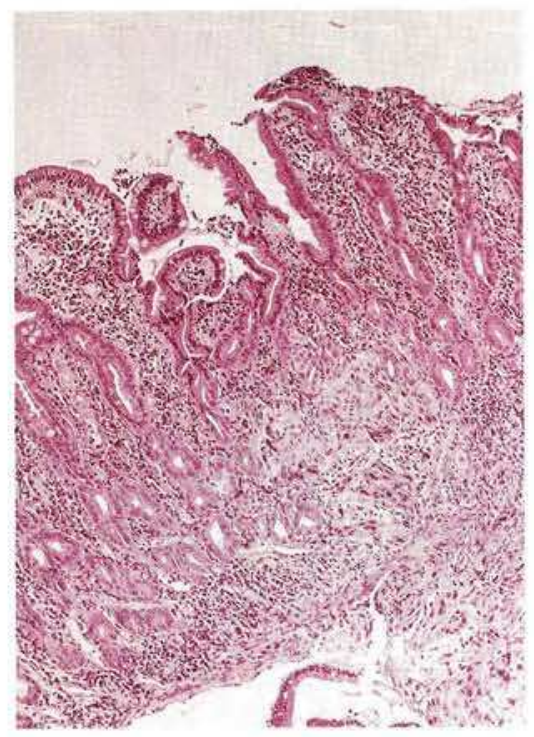

Figure 2

Microscopic picture showing squamous-cell carcinoma of the lung in duodenal mucosa (hematoxylin-eosin). 


\section{References}

1. Richie RE, Reynolds VH, Sawyers $J L$ : Tumor metastases to the small bowel from extraabdominal sites. South Med J 1973; 66: 1383-1387.

2. Silverstein FE, Tytgat NJT: Small bowel. In: Silverstein FE, Tytgat NJT, eds. Atlas of gastrointestinal endoscopy. Philadelphia: Saunders, 1987: 8.16-8.20.

3. McNeill PM, Wagman LD, Neifeld JP: Small-bowel metastases from primary carcinoma of the lung. Cancer 1987; 59: 1486-1489.

4. Steinhart $A H$, Cohen $L B$, Hegele $R$ et al.: Upper gastrointestinal bleeding due to superior mesenteric artery to duodenum fistula: rare complication of metastatic lung carcinoma. Am J Gastroenterol 1991; 86: 771-774.

5. Gonzalez GD, Bottsford JE Jr, McCulloch JH: Metastatic adenocarcinoma from the lung occurring as occult gastrointestinal bleeding. South Med J 1983; 76: 1035-1036.

\section{Corresponding Author}

I. Raijman, M.D., Division of Gastroenterology

University of Txas, 6431 Fannin MSB 4.234

Houston, TX 77030 